Víctor Jeifets - Lazar Jeifets, Los latinoamericanos en la Celebración del X Aniversario de la Revolución Rusa y la preparacion del Congreso Sindical Latinoamericano, Izquierdas, 48, noviembre 2019:64-86

\title{
Los latinoamericanos en la Celebración del X Aniversario de la Revolución Rusa y la preparacion del Congreso Sindical Latinoamericano
}

\author{
The Latin American delegation in the Celebration of Xth Anniversary of the Russian \\ Revolution and the preparation of the Latin American Trade Union Congress
}

Víctor L. Jeifets* ${ }^{*}$ Lazar S. Jeifets**

Resumen: El presente artículo tiene el objetivo de investigar la apertura de las fronteras de la URSS al mundo con el propósito de expandir las ideas comunistas, enseñar la experiencia positiva en el camino de construcción al socialismo, atraer el apoyo de los sindicatos e inteliguentsia mundiales que simpatizaban a la causa de la Unión Soviética y de la revolución bolchevique, así como fortalecer su posición en la arena internacional y obtener un amplio respaldo en caso de posibles agresiones imperialistas. Con dicho propósito, en 1927 fueron convocados varios eventos en Moscú: la celebración del X aniversario de la Revolución de Octubre y el Congreso de Amigos de la URSS, en los que participaron numerosos representantes de los sindicatos latinoamericanos e intelectuales del Viejo y Nuevo mundos. No obstante, a pesar de los grandes esfuerzos realizados en este ámbito, el trabajo podría reducirse a cenizas por el genio, simpatías y antipatías de algunos de sus organizadores (por ejemplo, de Victorio Codovilla y el "caso de Rafael Greco" iniciado por él). En todo caso, se puede concluir, que la realización del objetivo fue exitosa. Tras las celebraciones en Moscú se inició el trabajo de aproximación de las relaciones de la Comintern y de la URSS con sus correligionarios en el litoral del Océano Pacífico y en América Latina, que culminó con la constitución de la Confederación Sindical Latinoamericana. La importancia y novedad de la presente investigación se destaca en que por primera vez los autores utilizan los datos obtenidos del Archivo Estatal Ruso de Historia Política y Social, cotejándolos con los datos hemerográficos y la bibliografía para informar sobre los pormenores de la preparación de los viajes de los delegados latinoamericanos a Moscú en 1927.

Palabras clave: Comintern, X aniversario de la Revolución de Octubre, Victorio Codovilla, Rafael Greco, Confederación Sindical Latinoamericana.

\begin{abstract}
The present article takes as the target to investigate the opening of the borders of the USSR to the world with the intention of expanding the Communist ideas, of teaching the positive experience in the way of construction of the socialism, of attracting the support of the foreign trade unions and intellectuals that were sympathizing to the cause of the Soviet Union and the Bolshevik Revolution, and strengthening of its position in the international stand with a purpose to obtain wide support in case of possible imperialist aggression. With the above mentioned intention in 1927 several events were summoned in Moscow: the celebration of Xth anniversary of the Revolution of October and of the Friends of the USSR Congress; both of them were attended by numerous representatives of the Latin American Trade Unions and
\end{abstract}

\footnotetext{
${ }^{*}$ Ruso. Doctor titular, profesor de Saint-Petersburg State University y profesor de la Universidad de Instrumentación Aerospacial de San Petersburgo.jeifets@gmail.com. Coautor.

** Ruso. Doctor titular, profesor de Saint-Petersburg State University. jeifets@gmail.com Coautor.
} 
intellectuals from the Old and New Worlds. Nevertheless, in spite of the big efforts realized in this one ambience, the work might come down to ashes for the genius, sympathies and antipathies of some its organizers (for example, Victorio Codovilla) initiated and demonstrated during the so called "Rafael Greco case". In any case, it is possible to conclude, that the achievement of the target was successful. After the celebrations in Moscow there began the work of approaching of the relations between the Comintern and the USSR with its coreligionists in the coast of the Pacific Ocean and in Latin America, that was followed by the foundation of the Latin-American Trade Union Confederation. The importance and innovation of the present investigation stands out in that for the first time the authors use the obtained information of the Russian State Archive of the Political and Social History comparing it with the media and bibliography to report on the particulars of the preparation of the trips of the Latin-American delegates to Moscow in 1927.

Keywords: Comintern, Xth Anniversary of the October Revolution, Victorio Codovilla, Rafael Greco, Latin American Trade Union Confederation.

Recibido: 14 junio 2018 Aceptado 26 agosto 2018

\section{Preámbulo}

La celebración del X aniversario de la Revolución de Octubre dio un impulso importante para la intensificación de las relaciones entre la Internacional Comunista -la III Internacional o la Comintern-, y las organizaciones internacionales sometidas bajo su control en el movimiento revolucionario de América Latina. Durante la preparación de la celebración fue tomada en cuenta la experiencia de la visita a la URSS de las delegaciones obreras extranjeras, la primera de las cuales (la inglesa) llegó al país en 1920. El dirigente soviético Vladimir Lenin destacaba la importancia extrema de tales viajes de familiarización "para desenmascarar las mentiras divulgadas por la propaganda burguesa". ${ }^{1}$

En 1927, uno de los dirigentes de la Comintern, el finlandés Otto Kuusinen (quien era a la vez el Secretario del Comité Ejecutivo de la Comintern, CEIC), al valorar los resultados del intercambio de delegaciones, se enfocaba en la posibilidad de que los representantes de los obreros extranjeros vieran "con sus propios ojos..., que la construcción del socialismo en la URSS es posible". ${ }^{2}$ Gracias a la preparación del evento fue posible acumular los recursos organizacionales y financieros de la Comintern, la Internacional Sindical Roja (ISR), el Socorro Rojo Internacional (SRI) y otras organizaciones internacionales del frente comunista, uniendo sus esfuerzos con las actividades de los sindicatos soviéticos y la Sociedad Pan-Soviética de Relaciones Culturales con el Exterior (VOKS, por sus siglas en ruso).

Algunos materiales sobre la participación extranjera en la celebración del aniversario de la Revolución de Octubre fueron publicados ya en 1927 (y de manera bastante extensa) en la prensa de la URSS, además, varios latinoamericanos, al regresar a sus patrias, describieron sus experiencias en las crónicas y artículos. Esta apertura parcial externa de la Unión Soviética evidenció una mera euforia que se presenciaba en la Comintern sobre el progreso alcanzado para entonces por el movimiento comunista de América Latina,

\footnotetext{
1 Vladimir Illich Lénin, "Discurso en la Conferencia amplia de obreros y soldados del Ejército Rojo en el barrio RogózhskoSímonovskiy el 13 de mayo de 1920. Reportaje periodístico", en Vladimir Illich Lénin, Polnoie Sobraniie Sochinenii, Moscú, Politizdat, 1981, 121.

2 Otto Kuusinen, “Aliados de la Unión Soviética”, Právda, Moscú, a 6-7 de noviembre de 1927.
} 
que poco a poco empezó a ser considerado por Moscú como una base con perspectivas serias para toda la revolución mundial. Al mismo tiempo, se quedó fuera del alcance de gran público la parte secreta del evento, las discusiones, en las que participaban los delegados latinoamericanos en la sede de la Comintern para debatir los detalles del desarrollo del movimiento obrero y de izquierda continental.

Tuvieron que pasar varias décadas para que los investigadores reciban posibilidades de restaurar los pormenores de aquellos sucesos revisando los materiales contenidos en los archivos. Gracias a los datos obtenidos, quedó en evidencia que las informaciones publicadas apenas revelaban la punta del iceberg. Al mismo tiempo, las obras "clásicas" sobre historia del comunismo sólo se referían brevemente a la importancia de la celebración del X aniversario de la Revolución de Octubre para el desarrollo del movimiento obrero latinoamericano y sus relaciones con la Comintern. Los autores describen la participación de los representantes latinoamericanos en la Celebración del aniversario de la Revolución de Octubre sólo en líneas generales. ${ }^{3}$ Los trabajos publicados recientemente sobre la historia de los Partidos Comunistas ${ }^{4}$ y el movimiento obrero en los países de América Latina no cambiaron sustancialmente el estado de las cosas presente en la historiografía (los viajes de los delegados latinoamericanos a Moscú en 1927 se quedan fuera del análisis de los investigadores). ${ }^{5}$ El estudio pormenorizado del investigador alemán Reiner Tosstorff tampoco es de mucha ayuda en este aspecto, pues el tema casi no es tocado en su libro ${ }^{6}$. El presente trabajo pretende hacer una aproximación para rellenar las lagunas historiográficas.

A través de este texto analizaremos los pormenores de organización de los viajes de los representantes latinoamericanos a los festejos del triunfo bolchevique en la URSS. Vemos una necesidad de analizar el significado de estos viajes y encuentros sostenidos por los delegados en Moscú para la construcción y despliegue del trabajo cominternista en Latinoamérica, y para la organización de los eventos en el continente. Los pormenores de esta historia hasta hace poco estuvieron guardados bajo siete llaves y solamente con la apertura parcial del Archivo en la Comintern en Moscú (RGASPI, por sus siglas en ruso) empiezan a aparecer ante el público.

Para alcanzar nuestros objetivos, hemos elaborado un texto dividido en tres secciones. En la primera nos concentraremos en la historia de la organización de los viajes y de la parte latinoamericana de los festejos. En segundo lugar, abordaremos el análisis de un caso especial, el "caso Rafael Greco" que marcó el inicio de la llegada de nuevo tipo de relaciones entre la Comintern y el movimiento comunista continental, es decir, del establecimiento del control estricto (de parte de Moscú) sobre los sindicatos afines a la ISR. En tercer lugar, nos enfocaremos al estudio de las preparaciones del Congreso Sindical Latinoamericano (1929) empezadas precisamente durante los viajes de los delegados obreros latinoamericanos hacia la Meca comunista.

Utilizaremos algunas fuentes hemerográficas soviéticas para obtener información de los acontecimientos referentes al tema del estudio. Sin embargo, la base principal del artículo serán los documentos de archivos rusos de primera mano, la correspondencia entre el CEIC, el Secretariado Sudamericano de la Comintern (SSAIC) y varios otros destinatarios. El trabajo tras bambalinas significaba en la Comintern una parte clave del funcionamiento de sus secciones nacionales, lo que enfrenta a los historiadores al reto de estudiarlo a partir del análisis de la correspondencia secreta. Con el propósito de averiguar y cotejar los pormenores de la historia de los acontecimientos investigados, contrastaremos las fuentes de archivo con la información publicada en la bibliografía existente y las memorias. Tal enfoque

\footnotetext{
3 Manuel Caballero, La Internacional Comunista y la revolucion latinoamericana, Caracas, Editora Alfa, 2006); Boris Goldenberg, Kommunismus in Lateinamerika, Stuttgart, Berlin, Köln, Mainz, Kohlhammer, 1971); Alexander, Robert J. Alexander, Communism in Latin America, New Jersey, Rutgers University Press, 1957.

${ }^{4}$ Hernán Camarero, A la conquista de la clase obrera. Los comunistas y el mundo del trabajo en la Argentina, 1920-1935, Buenos Aires: Siglo XXI, 2007; Angelina Rojas Blaquier, Primer Partido Comunista de Cuba. Sus tácticas y estrategias. 1925-1935, Tomos 1-2, Santiago de Cuba, Editorial Oriente, 2005.

5 Víctor Jeifets, Komintern i evolutsiia levogo dvizheniia Meksiki, San Petersburgo, Nauka, 2006.

${ }^{6}$ Reiner Tosstorf, The Red International of Labor Unions, Boston, Brill, 2004.
} 
permite entender mejor la esencia del desarrollo de los contactos entre el movimiento comunista y el sindicalismo latinoamericano y la sede de la revolución mundial, y evaluar de manera precisa los asuntos que no podrían ser discutidos o aclarados públicamente dado su carácter confidencial.

\section{Los latinoamericanos en la Patria del proletariado mundial}

Los dirigentes bolcheviques se encargaron de dar una trascendencia internacional a los festejos con motivo del X aniversario de su triunfo, basándose sobre los antecedentes y simpatías que ya sumaban varios años, según indica M. Loyola. ${ }^{7}$ En varias naciones latinoamericanos ya habían surgido Asociaciones de Amigos de la URSS, siendo la Argentina la primera entre ellas.

La culminación del evento tenía que ser la celebración en Moscú del Congreso de Amigos de la URSS, "para discutir los asuntos de la defensa y amenazas militares a la Unión Soviética y la estrategia del proletariado mundial para proteger la primera República de obreros y campesinos en el mundo". Este amplio foro de los representantes de todos los continentes, gente con diferentes convicciones políticas, a los que unía el sentido de la solidaridad con la Unión Soviética, según sus organizadores, tenía que ser "un esfuerzo interesante de crear un frente unido de obreros de distintas corrientes, campesinos, luchadores con nuevas guerras imperialistas que no pertenecían a la clase obrera, contra el Imperialismo". 8 Según las estimaciones de Komsomólskaya Právda hechas el 11 de noviembre de 1927, 947 delegados en total participaron en el Congreso. América Latina estuvo representada en el Presídium del Congreso por los delegados de Argentina, México, Brasil, Ecuador, Uruguay, Colombia y Venezuela. ${ }^{9}$

Para calcular el presupuesto el Comité Organizador pidió a las organizaciones interesadas en acudir, y a algunas personas en particular, facilitar los datos sobre el presupuesto necesario para el viaje. ${ }^{10}$ Es imposible hoy día darse cuenta sobre las sumas exactas gastadas en los viajes de los delegados latinoamericanos a Moscú, sin embargo, algunos documentos revelan el esquema del financiamiento usado antes y durante el evento. En estos papeles se menciona la necesidad de pagar el viaje de los invitados hasta la frontera de la URSS; en caso de ausencia de toda la suma requerida, el Comité Organizador proponía a las organizaciones que estaban invitando a los visitantes ayudar con el viaje. La estancia en la URSS y, obviamente, el camino de vuelta, tenían generalmente que ser financiadas por la parte soviética, dada la escasez de recursos disponibles en los sindicatos latinoamericanos.

Este esquema, en todo caso, incluía los invitados que no militaban en los partidos comunistas o en los sindicatos pertenecientes a la Internacional Sindical Roja; en tales casos Moscú asumía por completo los gastos. Por ejemplo, el viaje de la delegación mexicana (a la cual acompañaba el chileno Rufino Rosas) costó a Moscú 2,770 dólares. Algunos documentos permiten revelar que el presupuesto medio para un delegado equivalía a 250 dólares. Aparte del dinero enviado desde la capital soviética había a veces otras fuentes de financiación, como, por ejemplo, suscripciones entre los obreros iniciadas por la Unión Sindical Argentina (USA). ${ }^{11}$ Sin embargo, este último remedio en las condiciones de América Latina no resultó ser eficaz para poder cubrir todas las sumas necesarias para los pasajes, estadía y viáticos de los delegados. Generalmente, los obreros ganaban tan poco que no eran capaces de prestar dinero para la organización de viajes.

\footnotetext{
7 Manuel Loyola, “La Asociación de amigos de la Unión Soviética en Chile, 1927-1943”, Estudos Ibero-Americanos 42:1, Porto Alegre, 2016, 312.

8 Izvéstia, el 11 de octubre y 5 de noviembre de 1927.

9 Lazar Jeifets, ““Para contar la verdad sobre la URSS”. (Primeras delegaciones latinoamericanas en la Unión Soviética)", Latinskaia Amérika, 12, Moscú, 1982, 73-83.

10 “Telegramas de Codovilla a L. Sala (Uruguay), J.F. Carolis (Ecuador), Penelón, Romo, Alonso (Argentina)", en El Archivo Estatal Ruso de la Historia Político-Social (RGASPI por sus siglas en ruso), F. 495, inv. 79, exp. 25, ff. 42-44

11 “Telegramas de Codovilla a Penelón, al deputado Pérez Leiros (Buenos Aires), Fritz Bach (México)", 1927. RGASPI, Moscú. F. 495, inv. 79, exp. 25, ff. 47, 53; Právda, el 28 de septiembre de 1927.
} 
La posibilidad de invitar a Moscú a un amplio y representativo grupo de latinoamericanos por primera vez en la historia de la Comintern persiguió al mismo tiempo varios objetivos. En este momento aparecieron buenas perspectivas para entrelazar los contactos organizativos y de ideas entre la III Internacional y las organizaciones afiliadas a esta con el movimiento revolucionario de América Latina. Según afirmaba el "patriarca" de la historiografía del movimiento obrero de América Latina, Robert J. Alexander, fue durante estas conversaciones cuando "se fundó la base de la primera organización comunista de obreros a escala mundial, o sea, la Confederación Sindical Latinoamericana, CSLA".12

El Comité Organizador de la Celebración del X aniversario de la Revolución bolchevique y las organizaciones afiliadas a la Comintern mandaron varias invitaciones a los partidos políticos, sindicatos latinoamericanos, a los intelectuales que simpatizaban con la URSS, para que participaran como invitados en "la celebración solemne de nuestra Revolución" y "con el objetivo de conocer el movimiento sindical y la vida económica de la Unión Soviética". ${ }^{13}$ Uno de los encargados de organizar los viajes de los latinoamericanos a Moscú era el argentino Victorio Codovilla, quien en 1926-1928 fuera representante del Partido Comunista de Argentina (PCA) en el Comité Ejecutivo de la Internacional Comunista y miembro suplente del Presídium del CEIC desde 1926. Más tarde fue designado dirigente del Secretariado Sudamericano de la Comintern, fue miembro del Buró del Secretariado Latinoamericano de la Comintern, jefe de la delegación del CEIC en España, miembro del Comité Ejecutivo y Secretariado del PCA, durante muchos años fungió como presidente del PCA. ${ }^{14}$ Siendo responsable del sector latinoamericano en el Comité, Codovilla informó al SSAIC con sede en Buenos Aires, sobre la disposición de los sindicatos soviéticos para invitar a los representantes de las organizaciones de obreras de los países "a costa del dinero destinado para recibir las delegaciones", y ordenó al Secretariado organizar una campaña de propaganda en la prensa nacional para difundir la Celebración e incentivar la participación en ella de los delegados sudamericanos. ${ }^{15}$

Desde el principio se proyectaba que la celebración sería un evento a gran escala que no se limitaría a los marcos del movimiento comunista, consecuentemente, Codovilla solicitó -a través de un telegramaal dirigente del Partido Socialista de Argentina (PSA), editor en jefe de "La Vanguardia", Americo Ghioldi (hermano de los dos prominentes comunistas argentinos, Rodolfo y Orestes Ghioldi), publicar en su periódico los materiales sobre el aniversario.

Analizando el texto del telegrama, se pueden deducir las personas y el tipo de las delegaciones invitadas, así como las organizaciones que patrocinaban la recepción. El Consejo Central de la Unión Pan-Soviética de Sindicatos (VTsSPS por sus siglas en ruso), invitaba a los delegados de tres centros sindicales de Argentina (dos representantes de cada uno) y a dos centros sindicales de Uruguay (un delegado para cada uno). La Confederación General de Trabajadores de Brasil podía enviar a tres personas. Los sindicatos soviéticos contaban con acoger a dos delegados de Chile, Colombia y Cuba, uno de Bolivia, Perú, Paraguay y Ecuador. Por su parte, la Unión Pan-Rusa de Cooperativas Agrícolas invitó a dos representantes de La Federación Agrícola de Argentina y la Federación Campesina de Brasil. Entre los latinoamericanos invitados por la VOKS, estaban el diputado socialista argentino Alfredo Palacios, otro socialista e intelectual argentino, Alejandro Castineiras, uno de los fundadores de la Unión

\footnotetext{
12 Robert J. Alexander, Op. Cit., 34.

13 "Telegrama del Presidente de la Comisión de Relaciones internacionales del CC de la Unión Pan-Soviética de los Sindicatos Yanglóm a Alonso (la Unión Sindical de Argentina)", Moscú, 1927. RGASPI, Moscú. F. 495, inv. 134, exp. 105 , f. 70.

14 Lazar Jeifets, Víctor Jeifets, América Latina en la Internacional Comunista, 1919-1943. Diccionario biográfico, Santiago, Ariadna, 2015; Horacio Tarcus (dir.), Diccionario biográfico de la izquierda argentina, Buenos Aires, Emece, 2007.

15 “Telegrama de V. Codovilla a Penelón”, Moscú, antes del 12 de septiembre de 1927. RGASPI, Moscú. F. 495, inv. 134, exp. 106, f. 9.
} 
Latinoamericana, Dr. Carlos Sánchez Viamonte. Esta lista representaba el panorama de los países que de algún u otro modo estaban bajo la influencia del SSAIC. ${ }^{16}$

Para contar con un amplio espectro de representantes latinoamericanos durante la Celebración, el Comité Organizador solicitó el apoyo financiero a varios partidos comunistas, organizaciones internacionales, dirigentes de sociedades coterráneas latinoamericanas en diferentes países. Así, por ejemplo, el cubano Leonardo Fernández Sánchez que estaba en Paris, negociaba -por encomienda del Comité Organizador- el viaje a Moscú del colombiano José María Vargas Vila, quen vivía en aquel tiempo en Madrid, del líder de la Asociación Cubana de Veteranos y Patriotas, E. Hernández y su hijo, Dr. Eusebio Adolfo Hernández, que era uno de los fundadores de la Universidad Popular "José Marti”"; del uruguayo Carlos Quijano, que se desempeñaba como el secretario general de la Asociación General de los Estudiantes Latinoamericanos (AGELA). ${ }^{17}$

Fue Leonardo Fernández Sánchez quien informó a Moscú sobre la imposibilidad del viaje de dos delegados de la Confederación Nacional Obrera de Cuba (CNOC) por razones financieras, y pedía resolver el problema urgentemente. El revolucionario cubano indicaba a la Comintern el retraso en el envío del dinero por parte del Comité Organizador, "sólo se podría enviar a los delegados designados con anticipación y solo si encontráramos urgentemente un barco que zarpara hacia allá". El cubano garantizaba que el dinero destinado al viaje se gastaría sólo con ese fin y, en caso de que los delegados no pudieran asistir, sería devuelto. ${ }^{18}$

En teoría, la celebración del X aniversario de la revolución bolchevique abría posibilidades de cimentar las bases de cooperación entre diferentes organizaciones de izquierda, de intelectuales independientes y de grupos de demócratas antimperialistas (una alianza que en los años treinta se llamaría el Frente Popular), intercambiar opiniones, encontrar estrategias comunes para abordar problemas del desarrollo del movimiento revolucionario. No obstante, el comportamiento de la Comintern para elegir a los delegados dificultaba la realización de los objetivos (en el caso de América Latina, nos referimos a la actitud de Victorio Codovilla, que se guiaba por sus simpatías o antipatías personales). Al declarar su voluntad de llevar una gran cantidad de simpatizantes de la Revolución de Octubre a los eventos de Moscú, la III Internacional pretendía atraer, sobre todo, a la gente que le convenía al partido comunista mundial, o sea, la gente que aspiraba a unirse a los planteamientos político-ideológicos ofrecidos.

La selección primaria de las organizaciones invitadas hecha por el Comité Organizador no imponía ningún prerrequisito a la composición de las delegaciones (a excepción de los intelectuales a los que invitaban personalmente). Aun así, durante la etapa preparatoria, al conocer los apellidos de supuestos delegados, en Moscú decidieron llevar a cabo la selección. Codovilla, sin explicar las razones de su actitud amonestó al Secretariado Sudamericano de la Comintern por proponer sin consulta previa la candidatura de Bartolomé Bossio como delegado de la Liga Antiimperialista de Argentina. El argentino advirtió que "de este método no saldrá nada serio" y exigió proponer a "otro intelectual de izquierda listo para salir de inmediato como el representante de la Liga". ${ }^{19}$ Las motivaciones de Codovilla fueron claras: el PCA a diferencia del PC de México- no controlaba a la Liga Antimperialista en su país y tardó muchísimo para arrebatar la bandera antimperialista a la disidencia chispista. ${ }^{20} \mathrm{El}$ representante de PCA también negó

\footnotetext{
16 “Telegrama de V. Codovilla a A. Ghioldi”, Moscú, 1927. RGASPI, Moscú. F. 495, inv. 79, exp. 25, f. 55; “Telegrama de Codovilla a A. Castineiras”, Moscú, 12 de septiembre de 1927. RGASPI, Moscú. F. 495, inv. 79, exp. 25, f. 10;”’Telegrama de Codovilla al Dr. A. Palacios”, Moscú, 12 de septiembre de 1927. RGASPI, Moscú. F. 495, inv. 79, exp. 25, f. 11.

${ }_{17}$ Según los datos de la prensa soviética, la delegación de los pueblos coloniales estuvo compuesta por C. Quijano (América Central y Sudamérica), E. Hernández (en el texto de la publicación se menciona como “Esseboi Hermánsets”), E. Ávila Martínez, L. Fernández Sánchez (Cuba), J. Vasconcelos (México) y Vargas Vila (Colombia). Právda, 21 de octubre de 1927.

18 "Carta de L. Fernández Sánchez a V. Codovilla”, París, el 3 de octubre de 1927. RGASPI, Moscú. F. 503, inv. 1, exp. 25, f. 30.

19 “Telegrama de Codovilla a Concentrus”, 1927. RGASPI, Moscú. F. 495, inv. 79, exp. 25, f. 41.

${ }^{20}$ Daniel Kersfeld, Contra el Imperio. Historia de la Liga Antimperialista de las Américas, México, Siglo XXI, 2012.
} 
rotundamente la posibilidad de llevar a Moscú como delegado sindical al "chispista"21 Rafael Greco, al caracterizarlo como "una persona problemática". ${ }^{22}$ Y nuevamente Codovilla evitó presentar algunos motivos de su posición, a pesar de que para cualquiera que conociera un poco la situación en el movimiento obrero argentino, el asunto quedaba claro: el dirigente del Sindicato de Obreros Metalúrgicos Rafael Greco, expulsado dos veces del PCA (en 1923 como "centrista y oportunista" y en 1926 por "chispista"), sería la "oveja negra" en la celebración de la solidaridad con la URSS.

Como sea, el resultado del meticuloso trabajo preparatorio fue la llegada de una delegación latinoamericana bastante representativa a la celebración. Hasta entonces Moscú jamás había visto tantos latinoamericanos al mismo tiempo. Los miembros del Comité Central de la Unión Sindical de Argentina, Atilio Biondi, Martín García y Abraham Réznik, el secretario del Sindicato de Obreros de Construcción bonaerense, Prospero Malvestiti, el secretario del Consejo Sindical de la Provincia de Córdoba, Antonio Maruenda llegaron desde Argentina. La Federación de Jóvenes Comunistas de este país fue representada por el obrero-ebanista Solomón Elguer, mientras los intelectuales antiimperialistas delegaron a Moscú al escritor Manuel Ugarte (llegó a la URSS como miembro de la delegación internacional de la Liga del Trabajo Intelectual y la Liga Antiimperialista) y al periodista Arturo Orzabal Quintana.

Entre los representantes de la delegación mexicana se destacaban el ex-senador Luis G. Monzón (miembro del Partido Comunista de México y de la sección nacional del Socorro Rojo Internacional), los enviados de los obreros petroleros de Tampico, J. Montemayor y R. Maren, el director del Museo Nacional Manuel Mendizábal, ${ }^{23}$ Samuel Ramos Magaña de la Universidad Nacional, el secretario general del Sindicato de Trabajadores Ferrocarrileros y del Transporte, Elías Barrios, los delegados de la Liga Nacional Campesina, Pablo Méndez y José Guadalupe Rodríguez Favela, el secretario del Comité Central del Sindicato de Trabajadores Mineros, Lauro Cisneros. Un comunista mexicano de procedencia italiana, Vittorio Vidali (Carlos Contreras), fue a Moscú como otro representante de los trabajadores ferroviarios de México (antes de llegar a México había sido exiliado de los EEUU por participar activamente en la defensa de los anarquistas Sacco y Vanzetti, encarcelados y ejecutados por la justicia estadounidense). El muralista comunista mexicano Diego Rivera representó el continente como miembro de la delegación de la Organización de Ayuda Internacional de los Trabajadores y de la Liga Antiimperialista de las Américas (LADLA).

Aparte de los argentinos y mexicanos en el evento participaron representantes de Colombia (el miembro del Partido Socialista Revolucionario Guillermo Hernández Rodríguez), Brasil (el comunista y militante sindical Heitor Ferreira Lima), Uruguay (comunistas Martín Simone y Carlos Imaz), Ecuador (Ricardo Paredes), Venezuela (Salvador de la Plaza y Cármen Fortoul), Cuba (Leonardo Fernández Sánchez), Guatemala (Luis Villagrán), Chile (Rufino Rosas).

Por cierto, algunos de los delegados de América Latina (el argentino Solomón Elguer, el uruguayo Carlos Ímaz, el brasileño Heitor Ferreira Lima, la venezolana Carmen Fortoul y el colombiano Guillermo Hernández Rodríguez, habían sido seleccionados con anterioridad para realizar estudios en la Escuela Internacional Leninista (ELI) ${ }^{24}$, y el Comité Organizador aprovechó las circunstancias conscientemente con el propósito de ahorrar dinero.

Fue invitado el director del periódico La Semana, Sergio Carbó, de La Habana, que estaba en París. Más tarde él publicó una serie de 24 artículos en su periódico y escribió el libro "Un viaje a la Rusia Roja"

\footnotetext{
${ }_{21}$ El Partido Comunista Obrero de Argentina fue formado por un grupo de disidentes izquierdistas que habían abandonado el PCA. El nombre del periódico ("La Chispa") editado por el PCOA motivó la aparición del nombre extra-oficial del Partido, los 'chispistas'. Véase más detalles en Hernán Camarero, Op. Cit.

22 “Telegrama de Codovilla a J. Penelón”, 1927. RGASPI, Moscú. F. 495, inv. 79, exp. 25, f. 45.

23 Incluso para algunos delegados de los países donde las organizaciones de izquierda funcionaban legalmente, el viaje a la URSS se topaba con varios problemas. Por ejemplo, las autoridades mexicanas inicialmente negaron la salida del país a M. Mendizábal. Ver: "Denegación de permiso de viaje", Právda, el 21 de octubre de 1927.

${ }^{24}$ Lazar Jeifets, Víctor Jeifets, "La Comintern y la formación de militantes comunistas latinoamericanos”, Izquierdas, 31, 2016, $130-161$.
} 
(1928). Algunos invitados por motivos personales no pudieron o no quisieron viajar a la URSS. Fue el caso de los argentinos mencionados arriba (Palacios, Castineiras y Sánchez Viamonte) y del Dr. Pedro J. de Zepeda, el hombre de confianza del rebelde nicaragüense Augusto C. Sandino, que fue invitado por el VOKS como representante del Partido Liberal de Nicaragua, el diputado argentino Pérez Leiros, el dirigente sindical brasileño João da Costa Pimenta, uno de los fundadores del PCB y luego candidato del Bloque Obrero y Campesino al parlamento de su país.

Los archivos de la Comintern no contienen datos sobre la participación en las celebraciones del presidente de la Federación de los Estudiantes de Uruguay, Cospomentaldo, aunque la prensa soviética destacaba su presencia. ${ }^{25}$ En publicaciones de las listas de delegaciones latinoamericanas los periódicos la URSS cometían errores que mostraban el nivel precario de conocimientos sobre el continente y la falta de trabajo informativo por parte del Comité Organizador. Así, se refirieron al mexicano José Guadalupe Rodríguez Favela como Rodríguez, "representante de organizaciones obreras de la colonia francesa Guadalupe", y al venezolano Salvador de la Plaza lo llamaron "representante de la Liga de la Lucha contra el Imperialismo y los Pueblos Coloniales Oprimidos en El Salvador", ${ }^{26}$ confundiendo en ambos casos los nombres con los países.

Sin duda alguna, los organizadores cumplieron con el objetivo de propagar las ideas y experiencia de la Revolución de Octubre. Así, ya durante la primera entrevista en tierra soviética los delegados obreros de Argentina formularon el objetivo de su llegada con suma brevedad: "Investigar meticulosamente la experiencia de la construcción del socialismo para contar la verdad sobre la URSS en diferentes reuniones de trabajadores y a través de la prensa" ${ }^{27}$ Esta oportunidad fue brindada a todos los invitados extranjeros. Los delegados latinoamericanos hicieron un viaje largo a través del país, visitando Leningrado, Odessa, Baku, Novonikolaevsk (hoy día Novosibirsk), Rostov-na-Donu, Kharkov, donde conocieron a los trabajadores, campesinos, intelectuales, soldados y comandantes del Ejército Rojo con el objetivo de "ver con sus propios ojos que la modernización comunista es una obra real y no una leyenda". Observaron lo que querían ver: "la película maravillosa sobre la lucha dura y aferrada, la lucha que hasta hace poco llevaban los obreros apretándose los cinturones. En la pantalla por muchos kilómetros aparecían ciudades industrializadas, viejas, encaminándose hacía nuevas formas de economía, clubs, colegios...". ${ }^{28}$

Los invitados latinoamericanos valoraron la experiencia de resolver la cuestión nacional en el país comunista. El peruano Arturo Orzabal en su discurso en Bakú expresó sus impresiones:

Solo en la Unión Soviética nosotros vemos que las nacionalidades se desarrollan libremente. Nosotros lo atribuimos a la gerencia hábil del partido comunista. [...] Pocos europeos y americanos sabían sobre la existencia de Azerbaiyán. Tal vez, este país estaría perdido en la historia sin la Revolución de Octubre. ${ }^{29}$

A los delegados latinoamericanos el gobierno soviético les brindó varias oportunidades de participar en las sesiones de los órganos del poder local. El militante sindical uruguayo Martín Simone dio las palabras de apertura en la sesión conmemorativa del soviet de Leningrado, en la que se discutían las perspectivas del desarrollo de la región. ${ }^{30} \mathrm{El}$ corresponsal del periódico argentino La Crítica, Lev Rudnítsky, describía su experiencia durante el trabajo del Comité Ejecutivo Pan-Soviético de los Soviets (VTsIk por sus siglas en ruso):

\footnotetext{
25 Iqvéstia, el 27 de septiembre y 27 de octubre de 1927; “Telegramas de V. Codovilla a Leiros, J. Pimenta”, 1927. RGASPI, Moscú. F. 495, inv. 79, exp. 25, ff. 49, 53.

26 Právda, el 13 de octubre de 1927.

27 Krásnaia Gazéta, Leningrado, el 1 de noviembre de 1927.

28 "Las delegaciones fortalecen la frente de la defensiva de la Unión Soviética", Komsomólskaya Právda, Moscú, el 6 de noviembre de 1927.

${ }_{29}$ Bakinskiy Rabóchiy, Baku, el 23 y 24 de noviembre de 1927.

30 "El Plénum del Consejo de Leningrado", Krásnaia Gazéta, el 1 de noviembre de 1927.
} 
... por primera vez escuché al camarada [Mijail] Kalínin, ${ }^{31}$ pero creo que él, aunque acostumbrado a dar discursos, estaba algo nervioso... Sin humo, sin frases inútiles, él es maceta que perfecciona cada curva del camino transcurrido. Sin pretensiones que son propias de los políticos burgueses, él dibujó el mapa del futuro... [En la sala] hay más gente con trajes de obreros, pero también hay los que están en chaquetas, en trajes nacionales de la periferia. ... Pero sorprendentemente todos saben alzar la voz. Se ve que todos sienten las grandes responsabilidades ante el país y ante el proletariado mundial. De ahí, en mi opinión, hay unanimidad: no existen ni ambiciones personales, ni el deseo egoísta de que gane la propia opinión... Es muy diferente de las intrigas de los politicastros burgueses. ${ }^{32}$

Los jefes de Estado soviéticos recibían varias veces a los delegados extranjeros abordando en pláticas con ellos diferentes problemas tales como la situación internacional y la política exterior de la URSS, la colectivización de la agricultura rusa u otros. Durante la recepción de los invitados a la celebración del aniversario de la revolución de 1917, Iosif Stalin destacó la obligación de los trabajadores soviéticos:

... rendir cuentas ante sus hermanos de la clase sobre todos los problemas de los que ellos quieren obtener respuestas. Nuestro Estado es una criatura del proletariado mundial. Los activistas de nuestro Estado solo cumplen el deber ante el proletariado mundial cuando rinden cuentas ante sus representantes. ${ }^{33}$

Al dirigirse a los participantes del Congreso Mundial de Amigos de la URSS, Manuel Ugarte -en nombre de América Latina- generalizó sus percepciones y experiencias durante el viaje a la Meca comunista y formuló los objetivos comunes entre los partidarios latinoamericanos de la Revolución de Octubre y la URSS:

...tenemos dos objetivos - la lucha contra el imperialismo, no a través del nacionalismo estricto, sino a través de los esfuerzos colectivos internacionales, y la lucha contra las clases opresoras por la modernización de nuestra sociedad... Aquí, en la URSS, nosotros conocimos una experiencia social excepcional, la más increíble, la más importante y determinante para todos en la historia de la humanidad. ${ }^{34} \mathrm{El}$ ejemplo de su gente que supo librarse del capital extranjero rapaz y hacerse el dueño real de su territorio infinito - decía él durante la entrevista al periódico Právda-inspira a la gente de América Latina. ${ }^{35}$

El llamamiento del Congreso a los obreros de todo el mundo hacía hincapié en que

...la guerra contra la URSS significa la guerra contra los trabajadores de todo el mundo, significa el respaldo de la reacción internacional más oscura en su deseo de hundir el movimiento obrero en todos los países y aplastar la lucha liberadora de los pueblos oprimidos.

Los participantes del congreso aspiraban a defender "la patria de los trabajadores, el pilar del mundo, hogar de la liberación, bastión del socialismo, con todas las fuerzas, de todas las maneras". ${ }^{36}$ Los

\footnotetext{
31 Mijail Ivanovich Kalínin (1875-1946) era un prominente miembro del Partido Comunista. Siendo militante del Partido SocialDemócrata Obrero Ruso desde 1898, luego se convirtió en miembro del CC del PC Ruso (bolchevique) en 1919 y miembro del Buró Político del PC Pan-Soviético desde 1926. Desde 1917 era miembro del Consejo del Comisariado del Pueblo para la Alimentación, desde el 1918 ocupaba el puesto del Comisario de Hacienda Ciudadana de la Unión de Comunas de la Región Norte y la Comuna de Obreros de Petrogrado. En 1919-1938 era presidente del Comité Central Ejecutivo de los Soviets. Desde el año de 1938 hasta marzo de 1946 fue presidente del Presídium del Consejo Supremo de la URSS.

32 "El Gobierno de los Sóviets y Gobiernos de la burguesía (la experiencia de un periodista argentino)", Komsomólskaia Právda, el 20 de octubre de 1927.

33 "Encuentro de Stálin con delegados extranjeros. El 5 de noviembre", Leningrádskaia právda, Leningrado, el 13 de noviembre de 1927.

34 "El Congreso Mundial de Amigos de la URSS", Právda, el 13 de noviembre de 1927.

35 "Las experiencias de los delegados extranjeros", Právda, el 10 de noviembre de 1927.

${ }^{36}$ Iqvéstia, el 15 de noviembre de 1927.
} 
representantes de la delegación latinoamericana en el Congreso hicieron una afirmación, aparte basándose en la "experiencia real rusa" y negando rotundamente "la existencia de los cuentos de hadas sobre la ineficacia del proletariado para manejar la vida económica y política de Estado". La delegación declaró la necesidad de respaldar sin vacilación alguna a la Unión Soviética que había fundado las bases de la modernización social en el mundo y llamó a proteger al país proletario de las agresiones de naciones imperialistas. ${ }^{37}$

Varios delegados latinoamericanos compartieron sus experiencias sobre su estancia en la URSS en la prensa, mítines y reuniones. Esta tradición existía desde el inicio de los contactos de las organizaciones revolucionarias latinoamericanas con la Comintern y la URSS. Casi todos los delegados de partidos comunistas y sindicatos que llegaron a Moscú, participaron en los actos de propaganda sobre la experiencia de la construcción soviética e ideas de la III Internacional. Así, para ejemplo, el chileno Luis Emilio Recabarren, participante del IV Congreso de la Comintern y el II Congreso de la Profintern en 1922, escribía luego sobre su viaje a la URSS:

... fui allí para ver qué había sido hecho en aquél momento, [para observar] las condiciones que llevarían el proletariado a la construcción del comunismo. Así, no fui para ver el comunismo en acción, como algunos quieren imaginar, sea por su propio ingenio o malicia. Repito, fui con grandes ilusiones de ver hasta dónde avanzó el trabajo sobre la preparación de la construcción de la sociedad comunista. ${ }^{38}$

Los chilenos obtenían la información sobre la experiencia de la construcción del socialismo de los artículos escritos por este prominente líder comunista, publicados en La Nación; más tarde estos textos sirvieron de base para los libros de Recabarren Qué vi en Rusi" y La Rusia Obreray Campesina. Los argentinos estaban recibiendo información acerca de la Rusia Soviética a través de las cartas de los miembros del Partido Comunista de Argentina, Mijail Alexandrovsky y Rodolfo Ghioldi, publicadas en las páginas del periódico comunista La Internacional. El delegado de Partido Comunista del Uruguay al IV Congreso de la Comintern, Francisco Pintos Pereyra, compartía sus experiencias en el diario partidario Justicia. Una serie de artículos preparados por el cubano Julio Antonio Mella, que había visitado a la URSS después de participar en el I Congreso Antiimperialista en Bruselas, fue publicada por el periódico del Partido Comunista mexicano El Machete.

Rodolfo Ghioldi intervenía con discursos sobre la Rusia Soviética ante el IV Congreso de PCA, mientras Francisco Pintos hizo lo mismo en el IX Congreso del Partido Comunista de Uruguay. ${ }^{39}$ Manuel Díaz Ramírez contó a los delegados del Congreso de la CGT en México (1921), los pormenores de su plática con el dirigente soviético Vladimir Lenin, revelando al mismo tiempo la esencia de la política del partido bolchevique. ${ }^{40}$ Los enviados comunistas, al regresar de la URSS, comúnmente organizaban mítines y reuniones en varios centros obreros, cines, edificios sindicales. Una muestra de ello son varios folletos (que ahora están resguardados en el Museo de la Historia Contemporánea de Rusia, en Moscú) publicados por el PCA y los sindicatos comunistas que llamaban a obreros a reunirse con el argentino Miguel Contreras, delegado al V Congreso de la Comintern, el día 8 de noviembre de 1924 en la sede de la biblioteca "La luz para el pueblo", y el día 11 de noviembre, en la sala de la Sociedad Italiana, para escuchar su experiencia sobre "La Rusia Roja". Otro folleto invitaba a los miembros de los grupos

\footnotetext{
37 "La declaración de la delegación latinoamericana", en RGASPI, F. 495, inv. 79, exp. 26, f. 4.

38 Luis Emilio Recabarren, Iz̧brannye statyi i rechi, Moscú, Politizdát, 1977, 144.

39 Rodolfo Ghioldi, Izbrannye statyi i rechi, Moscú, Politizdát, 1979, 14; Francisco R. Pintos, "Vliyaniie leninizma na rabocheie dvizheniie Urugvaia", Novaya y Noveishaya istoria, 2, Moscú, 1960, 92.

40 Rosendo Salazar y José G. Escobedo, Las pugnas de 1 a gleba (Los albores del movimiento obrero en México, México, Editorial del PRI, 1972, 401-403.
} 
comunistas a escuchar la ponencia del representante argentino en la Comintern, Rodolfo Ghioldi, sobre la experiencia en el campo de la resolución del problema nacional en la URSS. ${ }^{41}$

El año 1927 dejó un rastro profundo en la historia del desarrollo de las relaciones entre la URSS, la Comintern y los movimientos revolucionarios de América Latina, y significó un hito memorable en el proceso del descubrimiento mutuo. Efectivamente, fue el encuentro de dos corrientes del movimiento revolucionario que impulsó el desarrollo de ideas y lazos organizacionales entre los revolucionarios latinoamericanos, la Comintern, el partido bolchevique y, por último, entre las secciones de la III Internacional. La participación de los delegados de América Latina en la celebración del X aniversario de la Revolución de Octubre no sólo contribuyó a la difusión de la información sobre la URSS en el mundo, sino también dio un empujón para iniciar una corriente informativa más amplia sobre la situación en el Nuevo mundo (casi desconocida por los rusos) y sobre el movimiento revolucionario del continente. Hasta ese momento la prensa soviética y la prensa mundial obrera no publicaban tanta información sobre la América Latina. Por el contrario, en 1927 la prensa soviética se llenó de entrevistas, discursos hechos en mítines obreros y pronunciados en el Congreso de Amigos de la URSS, más aún, estas informaciones aparecían no solamente en los periódicos de circulación nacional, sino además en los medios regionales. Contando a sus lectores sobre los visitantes amigos de la Unión Soviética, los periódicos daban al mismo tiempo un cuadro de vida de sus países, y las organizaciones revolucionarias que ellos representaban. El periódico Trud, la revista Mę̧hdunarodnoe rabochee dviz̧henie dieron a conocer informes detallados preparados por los delegados de los sindicatos revolucionarios de México, Uruguay, Brasil, Venezuela, Argentina, Ecuador, Chile, Colombia, Cuba los cuales fueron enviados al Bureau Ejecutivo de la Internacional Sindical Roja.

Desde aquel momento el movimiento revolucionario en América Latina se convirtió en el tema central en la prensa soviética, sus lectores obtuvieron la oportunidad de conocer mejor la vida de los habitantes de un continente lejano. A pesar de que la información era exclusivamente unilateral e ideológica, este hecho significó la ruptura en el desconocimiento sobre la realidad latinoamericana y marcaba el comienzo de los estudios sistemáticos de la situación en las naciones latinoamericanas.

\section{El caso de Rafael Greco}

La realización del gran objetivo ideológico de la celebración pudo crear las bases reales para el dialogo de diferentes sectores antiimperialistas y de izquierda latinoamericanos, aunque nunca se trató de formar un frente realmente amplio que absorbería todas las corrientes progresistas. No obstante, estas posibilidades casi terminaron en fiasco por carácter propio de Codovilla y su manera de entender los principios de la formación del Frente Único. En el centro del problema estaba "el caso de Rafael Greco", que causó muchos problemas entre los partidos comunistas, sindicatos y otras organizaciones de izquierda. La USA, a pesar de la oposición de Codovilla, envió como su delegado al Congreso a Moscú al chispista Rafaél Greco, guiándose, al parecer, por el entendimiento previo con los organizadores, en el que se había expresado el deseo de reunir en la celebración a todos los representantes de las organizaciones que sinceramente simpatizaban a la URSS. El delegado del PCA ante el CEIC percibió este acto de desobediencia como un insulto personal y ordenó negar el acceso a su ex-camarada de partido al Congreso de Amigos de la URSS, en base a una causa meramente formal: el apellido de Greco no estaba incluido en la lista de invitados por ninguna organización. ${ }^{42}$

Además, Codovilla manejó la redacción de una carta colectiva enviada al Comité Organizador de la celebración por un grupo de delegados argentinos que se oponían a "la presencia en Moscú del señor Greco que, según el carácter del trabajo realizado en sindicatos y en el ámbito político, y según los

${ }^{41}$ El Museo de la Historia Contemporánea de Rusia (Moscú), Fondo 11811/51a, ff. 353-11B; Fondo 11811/516, ff. 354-11B; Fondo 11811/29, ff. 354-11B.

42 “Las explicaciones de Gey a Pyátnitsky”, Moscú, el 17 de diciembre de 1927. RGASPI, Moscú. F. 495, inv. 190, exp. 137. 
métodos empleados por él, se le considera como el agente de los patrones". ${ }^{43}$ Greco fue acusado de participar en el grupo que organizó el asesinato del Secretario del Secretariado Sudamericano de la Internacional Comunista de las Juventudes, y dirigente de la FJCA, Enrique Müller; de presionar con ayuda de gente armada durante las reuniones sindicales, "obstaculizando a los revolucionarios activos tomar iniciativas en los sindicatos a pesar de que son la mayoría"; de expulsar a los comunistas y sus simpatizantes de los sindicatos. Los autores de la carta consideraban imperdonable el hecho de pertenecer a la agrupación chispista que, según ellos, "reunía toda la escoria del movimiento político y sindical del país, los miembros de cual fueron caracterizados infinitamente por la Internacional Comunista como agentes de los patrones por aspirar a sembrar discordia en las organizaciones de América Latina". ${ }^{44}$ Hay de suponer que el mismo Codovilla escribió gran parte del texto de la carta.

Las razones arriba expuestas dieron a los delegados que firmaron la carta un motivo para tildar a Greco como "un elemento no deseable en el movimiento obrero", ellos renunciaron a tener con él cualquier tipo de relación considerando que el objetivo de su viaje a la URSS era "ganar peso" para continuar su actividad contrarrevolucionaria al volver a Argentina. Bajo la carta aparecieron 14 firmas (sin apellidos) de los delegados de Chile, Cuba, Argentina, México, Uruguay, Venezuela, Ecuador, Brasil y Colombia. ${ }^{45}$ Bajo la orden de Codovilla este documento nunca fue presentado de manera oficial al Presídium del Congreso, cumpliendo su papel tras bambalinas. Cuando el Sindicato de los obreros metalúrgicos de Argentina exigió explicar el por qué Greco fue deportado de la URSS e inició la investigación del caso, el empleado responsable del Consejo Central de los Sindicatos Soviéticos, Constantin Gey (su firma estaba abajo del texto del telegrama) tuvo que escribir de manera confusa a los dirigentes del CEIC, Osip Piatnizky y Mauno Heimo, una cosa absolutamente absurda: "no firmé ningún telegrama a Argentina sobre el caso de Greco y no lo envié y no autoricé a nadie para firmar" y "no sé explicar las razones". Él solicitó los datos sobre la correspondencia de la Comintern respecto al "caso Greco", incluyendo los datos sobre "quién había firmado el telegrama" e insistía en "encontrar el motivo de la deportación de Greco" e impedir cualquier posibilidad de repetir este incidente. 46

A pesar de que en el telegrama del Comité Organizador se hacía hincapié en que la deportación de Greco "no era un acto hostil contra la USA y la Unión Soviética brindaba la bienvenida de sus delegados", la referida central sindical argentina expresó su protesta rotunda contra tal medida, al considerar que era “completamente inaceptable". La USA exigió explicar los motivos de la decisión tomada en Moscú. ${ }^{47} \mathrm{Al}$ mismo tiempo, en nombre de la Comisión de Organización de la Celebración fue enviado el telegrama al SSAIC dando a conocer la deportación de Rafael Greco y pidiendo publicar esa noticia en la prensa revolucionaria latinoamericana. ${ }^{48}$

El Secretario General de la Profintern, Solomón Losovsky, que estaba muy preocupado por este asunto pidió, a su vez, explicaciones al Secretariado Político del CEIC, subrayando que "la deportación se inició por iniciativa de Codovilla y este asunto altera las masas significativas de obreros de Buenos Aires". Este "asunto sin precedentes que tiene que ver con el representante de una organización laboral", según la opinión del dirigente de la Internacional Sindical Roja, requería una explicación, y en caso de no

\footnotetext{
43 “A la Comisaría de Organización de Delegaciones para el Aniversario de la Revolución de Octubre”, Moscú, el 8 de noviembre de 1927. RGASPI, Moscú. F. 495, inv. 190, exp. 137.

44 Ibidem.

45 Ibidem.

46 "Las explicaciones de Gey a Pyátnitsky", "Nota explicativa de cam. Gey al Secretariado del CEIC (Mauno Heimo)", Moscú, el 8 de diciembre de 1927. RGASPI, Moscú. F. 495, inv. 190, exp. 137.

47 "Telegrama de cam. Gey a Argentina”; Telegrama de T. González, el Secretario general de la USA, a S. Lozovsky”, Buenos Aires, el 27 de enero de 1928. RGASPI, Moscú. F. 495, inv. 190, exp. 137. 48 “Telegrama de Garl[andi] a Penelón”, Moscú, el 23 de noviembre de 1927. RGASPI, Moscú. F. 495, inv. 134, exp. 105, f. 42.
} 
tenerla, presentar disculpas ante los sindicatos bonaerenses y cancelar la medida tomada contra Rafael Greco. ${ }^{49}$

La investigación minuciosa realizada por el Comité Organizador mostró que Greco había llegado a Moscú a pesar de la directriz mandada a la embajada soviética en Berlín en la que le negaron el visado. Para aclarar los pormenores fue nombrada otra comisión encabezada por el Secretario del CEIC, Dmitry Manuilsky, que el 13 y 14 de noviembre tomó la decisión sobre la deportación del sindicalista argentino. El telegrama a Buenos Aires sobre las razones de su expulsión del país proletario fue escrito y firmado por Victorio Codovilla. El mismo lo presentó luego para validar ante la comisión especial del Secretariado del CEIC. La comisión evitó tomar alguna decisión concreta limitándose con la indicación de que el telegrama tendría que haber sido firmado no por la comisión de Manuilsky, sino por la comisión sobre los delegados extranjeros. Después de varios días Codovilla presentó el otro telegrama, esta vez el texto fue firmado por Constantin Gey (en representación de los sindicatos soviéticos) a pesar de que Gey ni siquiera participaba en la discusión del asunto. La práctica habitual cuando una persona del Comité Organizador firmaba un telegrama en nombre de otra para acelerar su envío, en el caso de Rafael Greco se realizó de otra manera. El "caso de Rafael Greco" tenía un claro trasfondo político y Codovilla no tenía ningunas ganas de mostrar en Argentina su participación en la expulsión del sindicalista. Él tendió una trampa a Constantin Gey, endorsando la responsabilidad política por la decisión tomada por el burócrata cominternista de origen argentino [Codovilla]..$^{50}$

Toda esta historia estuvo presente mucho tiempo después en la agenda política del movimiento revolucionario latinoamericano, creando así una situación bastante ambigua en las relaciones entre la III Internacional y la Internacional Sindical Roja, de un lado, y varias organizaciones laborales latinoamericanas, del otro. Por esta razón el Comité Ejecutivo de la Comintern exigía rotundamente explicar la situación y convencer a la gente que dudaba de que la relación de la III Internacional con el Frente Único fuera sincera, de que la decisión tomada fue justa. A fin de cuentas, la sede del partido comunista mundial decidió publicar en la prensa comunista el texto íntegro de la resolución tomada en Moscú. ${ }^{51}$ Victorio Codovilla, que para aquel momento ya estaba de vuelta en Argentina, consiguió desautorizar a Rafael Greco en su propio sindicato de obreros metalúrgicos, y el informe del delegado sobre el viaje a la URSS fue desaprobado.

Aun así, ello no significaba la victoria absoluta de Codovilla y el PCA sobre el chispista, sobre todo, porque el mismo PCA se debilitado seriamente por la crisis interna, la expulsión de su líder "histórico", José F. Penelón, y la ruptura posterior. Al entender la vulnerabilidad de su posición, el nuevo Secretario del Secretariado Sudamericano de la Comintern (Victorio Codovilla) hizo una jugada que fue bien recibida entre los dirigentes de Moscú. En su informe el argentino, como por si acaso, indicaba:

Nosotros olvidamos decir que un delegado del sindicato que había viajado a Moscú, intervino en plena discusión y dijo que [Rafael] Greco durante su visita corta a Moscú contactó con un "personaje importante" de la oposición. Pero el delegado de la USA [Unión Sindical de Argentina] no dijo el nombre, dijo que lo había olvidado. ${ }^{52}$

La insinuación explícita sobre el encuentro de Greco con León Trotsky o Grigory Zinóviev (o cualquiera de sus colegas) fue un golpe inequívoco a la reputación del chispista argentino en sectores

49 “Carta de A. Lozovsky al Secretariado Político del CEIC [Humbert-Droz]”, Moscú, el 27 de enero de 1928. RGASPI, Moscú. F. 495, inv. 190, exp. 137.

50 "Carta del jefe del Buró del Secretariado del CEIC Mauno Heimo al Departamento Organizativo de la Profintern, al camarada Gey”, Moscú, el 14 de diciembre de 1927. RGASPI, Moscú. F. 495, inv. 190, exp. 137.

51 "Carta de J. Humbert-Droz al Comité Central del Partido Comunista...”, Moscú, el 3 de marzo de 1928. RGASPI, Moscú. F. 495, inv. 79, exp. 43, f. 2. La carta fue enviada a Buenos Aires, Montevideo y la Ciudad de México.

52 "Carta del Secretario del SSAIC V. Codovilla al Secretariado Latinoamericano de la Comintern [a Humbert-Droz]", Buenos Aires, el 5 de septiembre de 1928. RGASPI, Moscú. F. 503, inv. 1, exp. 19, f. 37. 
amplios de la izquierda. Ya no importaba que tal encuentro fuera casi irreal, considerando además el estado especial de Rafael Greco en Moscú, dónde él estaba vigilado 24 horas por los órganos de la policía secreta soviética. El aire de desconfianza hacia los opositores en el Partido Comunista de la URSS era tan profundo dentro de los PP.CC. y varios sindicatos pro-comunistas que nadie quiso siquiera llevar la investigación para averiguar la certeza de los planteamientos hechos por Codovilla. Bastó con una sombra de duda sembrada por el secretario del SSAIC.

\section{En el camino hacia la formación del centro sindical continental}

Lo importante para Moscú fue que "el caso de Greco" no interrumpió los planes estratégicos de entonces para fundar las bases de una central sindical latinoamericana unida. La Internacional Sindical Roja, por la iniciativa de unos delegados sindicales participantes en la Celebración del X aniversario, convocó una Conferencia en la que se tomó la decisión de crear el Secretariado Sindical Latinoamericano y convocar en Montevideo el Congreso Sindical Continental. ${ }^{53}$ En la resolución firmada por los representantes de 11 organizaciones laborales y campesinas de Argentina, Uruguay, Colombia, Cuba, Chile y Ecuador (varios delegados de otras tres organizaciones sindicales habían participado en las discusiones, sin embargo, no pudieron firmar el documento final porque en ese momento salieron de la URSS) se hablaba de la necesidad de

...empezar el trabajo preparatorio en todos los países de América con el objetivo de unir a todas las organizaciones sindicales de clase para la lucha contra el Imperialismo de los Estados Unidos, contra la AFL (American Federation of Labor) imperialista, contra la ofensiva de la burguesía nacional, por establecer lazos estrechos de hermandad con el movimiento internacional obrero, para crear una Internacional ampliamente representativa de las clases que uniría a los sindicatos de todos los países, todas las razas y todos los continentes, con el objetivo de luchar juntos contra las guerras imperialistas y la libertad total del trabajo del poder del capital. ${ }^{54}$

La Internacional Sindical Roja demostró un gran operatividad y capacidad organizativa relacionada a la realización de estos planteamientos. Así, en febrero de 1928, Solomón Lozovsky se dirigió al Bureau Político del Comité Central del Partido Comunista pan-soviético, con la solicitud de presupuestar para la ISR fondos destinados a las actividades en las regiones de Asia, Océano Pacífico y América Latina, destacándolas como campos de actividad de suma importancia. ${ }^{55}$ Los sólidos argumentos a favor de esta decisión se hallaron en los resultados del trabajo ya realizado por el Secretariado del Océano Pacífico (SOP), que junto con el desarrollo del trabajo en China pudo atraer al lado de la ISR a los sindicatos filipinos y australianos, estableciendo contactos con el movimiento obrero en India y logrando organizar la edición en China de la revista en inglés "El obrero del Océano Pacífico". Durante este período el letón soviético Karl Yanson dirigía todo el trabajo ilegal de la Internacional Sindical Roja en el Extremo Oriente (Japón, China, Indonesia y otros países).

Para activar los esfuerzos comunistas en esta región se suponía crear un centro coordinador en Shanghai, organizando allí una editorial y para que fuera legal, fundar el Instituto sobre la Investigación de Industrias y Agricultura en el Extremo Oriente encabezado por el comunista estadounidense Earl Browder. Según las estimaciones del propio Lozovsky, el Secretariado del Océano Pacífico tendría en Shanghai un "aparato legal o cuasi-legal pequeño, pero maravilloso".

Se suponía, además que, al organizar el Secretariado Latinoamericano de la ISR de forma similar al Secretariado del Océano Pacífico, ambas estructuras tendrían que cooperar. Para mejorar el trabajo del

53 Právda, el 13 de diciembre de 1927.

${ }^{54}$ Grigori Dónskiy, Bor'ba za Latinskuyu Ameriku, Moscú-Leningrado, Moskóvskiy rabóchiy, 1928, 60.

55 "Nota de Lozovsky al Politburó del CC de VKPb/ "Sobre el presupuesto para el trabajo en la costa del Océano Pacífico y en América Latina””, Moscú, el 13 de febrero de 1928. RGASPI, Moscú. F. 534, inv. 8, exp. 94, f. 1. 
SOP, la central sindical internacional decidió fundar una nueva oficina en San Francisco. El comunista estadounidense Harrison George, que hablaba español, tenía que "mantener las relaciones con todos los países latinoamericanos del Océano Pacífico". Sin embargo, el Bureau Político del Partido Comunista de los EE.UU. rechazó la propuesta de que Harrison George se mudara a San Francisco, lo que la Profintern no tardó en denunciar como un sabotaje encubierto del trabajo antiimperialista que "podría dar beneficios sólo al Imperialismo americano". 56

$\mathrm{Al}$ informar al Bureau Político del PC de la URSS sobre la necesidad de realizar el trabajo de ambos secretariados y evaluar el presupuesto necesario, Lozovsky destacó la importancia del funcionamiento de las estructuras regionales, subrayando que el Secretariado Latinoamericano de la ISR que iba a abrirse "tendría suma importancia para todo el movimiento obrero en América Latina y merecería cualquier tipo de apoyo". ${ }^{57}$ Intentó convencer a los dirigentes del Partido Comunista pan-soviético sobre la necesidad de aumentar los gastos para el trabajo latinoamericano desde los 5,133 hasta los 72,000 mil rublos en divisas. Esto, en comparación con los porcentajes del año anterior, sería el aumento más radical del presupuesto destinado por Moscú para la región. En el presupuesto general de la ISR para el año 1928 la parte latinoamericana alcanzó 8.5\%, mientras que en 1927 estaba al nivel de menos del 1\%.58

Lozovsky, quien estaba bien enterado sobre las reglas del juego burocrático que suponía "el carácter de gastar el dinero popular con diligencia" (era la referencia al dinero emanado de la tesorería de la URSS) propuso dar un tijeretazo al presupuesto de un $10 \%$ para la ISR. Efectivamente, el Secretariado Latinoamericano recibió mucho menos dinero para sus actividades comparando con lo solicitado. En la columna del presupuesto de la ISR está indicada la suma de 30 mil rublos. Aparentemente, esta cifra muestra la cantidad a la que podría pretender la Internacional Sindical Roja. Pero, aun así, los gastos para las actividades sindicales en América Latina aumentaron casi 6 veces.

El procedimiento burocrático frenaba el mecanismo del trabajo de la ISR lanzado en América Latina. Según el plan de Solomón Lozovsky, inmediatamente después de la Conferencia Sindical Latinoamericana en Moscú, cinco o seis emisarios tenían que ser enviados al viaje por toda América Latina para preparar un Congreso Sindical Continental en Montevideo. La falta de decisión sobre el presupuesto ató al Buró Ejecutivo de la Internacional Sindical Roja de pies y manos. ${ }^{59}$

Después de que el Secretariado Latinoamericano de la ISR fue finalmente creado, Lozovsky se dirigió otra vez a los altos mandos del Partido Comunista de la URSS, esperando obtener su apoyo e indicando a los líderes bolcheviques que para mantener el trabajo del órgano regional "era imprescindible tener allá a su gente". El dirigente de la Sindical Roja nombró a Maurice Jaskin y Carlos Dujovne como posibles candidatos a puestos de emisarios del Secretariado Latinoamericano que deberían estar llevando a cabo actividad ilegal colaborando con "los camaradas locales y con la ayuda constante de la Profintern". ${ }^{60}$

El impulso organizacional a la idea de crear un centro continental de los sindicatos clasistas fue dado por la Segunda Conferencia Sindical Latinoamericana, que tuvo lugar en abril de 1928 en Moscú, luego de finalizar el trabajo del IV Congreso Mundial de la Profintern. En ella participaron 27 delegados de 10 países (México, Chile, Cuba, Colombia, Argentina, Uruguay, Ecuador, Perú, Brasil, Venezuela). Como invitados estaban presentes el Secretario General del Partido Comunista de la URSS, los delegados de la Confederation General Unitaire du Travail de Francia (CGTU) Auguste Herclet, Gastón Monmusseau, Alexandre Delobelle; los delegados de la Confederazione General di Lavoro de Italia, Santini y Giovanni

\footnotetext{
56 "Nota de Lozovsky al Secretariado Político del CEIC (a Pyátnitsky) "Sobre el trabajo de Brauder y Harrison George"”, Moscú, el 9 de febrero de 1929. RGASPI, Moscú. F. 495, inv. 3, exp. 143, f. 36.

57 "Nota de Lozovsky al Politburó del CC de VKPb/ "Sobre el presupuesto de los Secretariados de los sindicatos del Océano Pacífico y América Latina””, Moscú, el 2 de marzo de 1928, en RGASPI, F. 534, inv. 8, exp. 94, f. 7.

58 "Anexo a la nota del camarada Lozovsky", Moscú, el 13 de febrero de 1928. RGASPI, Moscú. F. 534, inv. 8, exp. 94 , f. 2.

59 "Nota [de Lozovsky] al Secretariado del CC del VKPb [a Kossior]", Moscú, el 12 abril de 1928. RGASPI, Moscú. F. 534, inv. 8, exp. 94, f. 12.

60 "Nota [de Lozovsky] al Secretariado del CC del VKPb [a Kossior]", Moscú, el 11 de mayo de 1928. RGASPI, Moscú. F. 534, inv. 8, exp. 94, f.21.
} 
Germanetto; Harrison George y William Dunne de la Trade Union Education and Propaganda League de los Estados Unidos, varios delegados de los sindicatos del Oriente, Inglaterra, Alemania, y Checoeslovaquia. ${ }^{61}$

Una peculiaridad importante de esta conferencia era la participación en ella (como en el Congreso de la Profintern) no sólo de comunistas, sino de representantes sindicales que no siempre estaban controlados por los respectivos Partidos Comunistas. A lo largo del encuentro que duró seis días, todos los delegados intervinieron con informes sobre los movimientos sindicales en sus países, para así desarrollar la vía de trabajo del movimiento latinoamericano; discutieron sobre los problemas de la organización sindical y la táctica de la lucha por los derechos laborales. Además, indicaron puntos débiles en el desarrollo organizativo del movimiento obrero. Entre los problemas presentes destacaba la situación de los campesinos y proletariado agrícola y la lucha contra el imperialismo. ${ }^{62}$

Según Lozovsky, los sindicatos en la mayoría de los países latinoamericanos "aún no salieron de los límites nacionales y por eso casi no mantenían relaciones con el movimiento sindical internacional. Los argentinos sabían poco sobre la situación en Colombia, los brasileños sobre los acontecimientos en Cuba, los peruanos no se enteraban lo que estaba pasando en Guatemala, etcétera". ${ }^{63}$ Para el movimiento obrero latinoamericano eran muy comunes

...las subidas y bajadas - decía el Secretario General de la Profintern- bruscas y muy rápidas, incluso inesperadas. Empieza un levantamiento que reúne muchos trabajadores, pero sigue poco y termina aplastado en cuestión de días. En países latinoamericanos nosotros encontramos el temperamento revolucionario, pero no basta sólo con él para llegar a la victoria. Tal vez sea suficiente para una huelga de 24 horas, pero no es suficiente para ganar a la burguesía. Además, es característico para los levantamientos de América Latina un nerviosismo; el levantamiento se desarrolla bien, pero luego no sabe a qué llegar.

Considerando la lucha contra el imperialismo como uno de los objetivos más importantes del movimiento obrero, los partidarios más grandes y firmes en ella, según Lozovsky, eran "la gran cantidad de campesinos, muchos de los cuales todavía están en situación de esclavos, la gran cantidad de campesinos que todavía están oprimidos por el régimen feudal", destacando "el papel especial" en el movimiento antiimperialista de la pequeña burguesía y la inteligencia que "tienen que ser tratados con bien conocida astucia". ${ }^{64}$

Valorando el trabajo de la conferencia, Lozovsky la calificó como "el segundo descubrimiento de América", y admitió que ni la Comintern ni la Internacional Sindical Roja se enteraban de manera suficiente sobre la situación del movimiento obrero continental, sobre "este gran almacén de energía antiimperialista, sobre estas fuerzas revolucionarias colosales que, a pesar de que tal vez estén en estado primitivo, tienen mucho potencial y grandes perspectivas". 65

Los delegados de la Conferencia Sindical Latinoamericana propusieron a la ISR tomar la iniciativa de convocar al Congreso Constituyente de la Confederación Sindical Latinoamericana. Recordemos que el trabajo activo de la Internacional Sindical Roja en este ámbito había empezado antes de la Segunda Conferencia y la discusión de todo el asunto en la Conferencia era la mera formalidad para guardar el

61 "El acta sobre la Constitución del Comité de Ayuda a la Confederación Latinoamericana de Trabajo, efectuada el lunes, el 3 de septiembre de 1928". RGASPI, Moscú. F. 534, inv. 4, exp. 219, ff. 105-106.

${ }^{62} \mathrm{La}$ información sobre la Segunda Conferencia Sindical Latinoamericana fue publicada en la prensa soviética. Ver: Trúd, el 8 , 10, 11, 12, 13 de abril de 1928.

63 Abram Losovsky, El movimiento sindical Latino Americano. Sus virtudes y sus defectos, Montevideo, Comité Pro Confederación Sindical Latino Americana, 1929, 1.

${ }^{64}$ Losovsky, Op. cit., 11-12, 26.

65 X Plenum Ispolkoma Kominterna. Vyp. 3. Ekonomicheskaia bor'ba i zadachi Kommunisticheskoi partii, Moscú, Gosudárstvennoe Izdátelstvo, 1929, 87. 
procedimiento. Tras algunas discusiones los conferencistas establecieron como la fecha de inauguración de la conferencia el 15 de mayo de 1929. El Comité Preparatorio del Congreso (el Secretariado temporal de la CSLA) incluyó varios representantes de sindicatos de Argentina, Brasil, Cuba, Colombia, Chile, Ecuador, México, Perú, Venezuela, Uruguay, Francia, Italia, el Secretariado del Océano Pacífico (se llevó a cabo una reunión especial de éste Secretariado con la participación de los delegados latinoamericanos y uno de los resultados de las pláticas fue la declaración de adhesión de los sindicatos que asistieron a la Segunda Conferencia al SOP). ${ }^{66} \mathrm{La}$ participación en el proceso de preparación de los sindicatos revolucionarios de los EEUU y Gran Bretaña fue declarada esencial para organizar la lucha antimperialista en dichos países. ${ }^{67} \mathrm{El}$ Comité Preparatorio nombró al órgano permanente con la sede en Montevideo y su subcomité caribeño en México, los objetivos del cual eran la coordinación del trabajo preparatorio del Congreso en la práctica y difusión de la información sobre él a todas las organizaciones interesadas.

La sesión constituyente del Comité se celebró el 3 de septiembre de 1929 en la capital uruguaya. La ciudad de Montevideo fue elegida como la sede del Comité por las razones de que el PCU era un partido legal y el sistema político del país permitía operar allí legalmente. Además, los sindicalistas uruguayos ya tenían experiencia en organizar encuentros internacionales de sindicatos (en 1926 en Montevideo se celebró el Congreso Continental de Marineros con participación de los delegados de los Obreros Industriales del Mundo (IWW por sus siglas en inglés) procedentes de los EEUU y Chile, de los sindicatos de Brasil, Uruguay, del sindicato soviético de trabajadores de transporte y de la Internacional Sindical Roja). ${ }^{68}$ Las organizaciones constituyentes acordaron no tener funciones ejecutivas, dejando así al futuro Congreso el derecho de determinar los poderes de la Confederación y sus órganos dirigentes, sin importar los bandos, la lucha feroz entre diferentes corrientes que separaban el movimiento obrero de América Latina. Eso era la condición preliminar definitiva para atraer al Congreso a nuevos participantes y, aún más importante, para facilitar las actividades de la futura Confederación Sindical Latinoamericana para reunir "todas las uniones sindicales de diferentes opiniones que seguían el principio de la lucha de clases y [entendían] la necesidad de la unión nacional e internacional para luchar contra la reacción y el imperialismo y la libertad de los trabajadores de todo el mundo". ${ }^{69}$

Entre los miembros de los órganos preparatorios del Congreso se podían encontrar no solamente a los dirigentes importantes de los partidos comunistas y de los sindicatos que estaban bajo su control, sino a los dirigentes de organizaciones de diferentes corrientes que participaban en el trabajo de la ISR o sus simpatizantes, o de los grupos que expresaban la solidaridad con la causa de la URSS. El símbolo de la futura unión fue la presidencia del sindicalista Atilio Biondi (miembro de la Unión Sindical Argentina que había firmado el Manifiesto de Moscú). Los participantes de la sesión no idealizaban la situación existente, aceptando la posibilidad de la aparición de desacuerdos serios como resultado de la vieja lucha de tendencias en determinados países y dentro del movimiento obrero en general. Sin embargo, ellos consideraban la posibilidad de nivelarlos, basándose en la necesidad de llegar a la unión de sindicatos clasistas.

El Comité Preparatorio se autoproclamó como una organización independiente, inclusive de la Internacional Sindical Roja, aunque expresándole gratitud por la iniciativa de celebrar las Conferencias en Moscú y su disposición de cooperar con la Profintern y con la Confederation General du Travailleurs Unitaire de Francia, siendo las organizaciones "más cercanas a la CSLA por su espíritu revolucionario". ${ }^{70}$ En total, las invitaciones para los participantes del Congreso fueron enviadas a más de 300 centrales nacionales y a algunos sindicatos autónomos.

\footnotetext{
66 Trúd, el 14 y 18 de abril de 1928.

67 "La Conferencia de los Sindicatos de América Latina", Trúd, el 13 de abril de 1928.

68 "El acta sobre la Constitución”, 106-107; Francisco R. Pintos, Profsoyuznoie dviž̨eniie Urugvaia, Moscú, Profizdat, $1964,181$.

69 "Carta del Secretario General del Comité Sindical Latinoamericano M. Contreras al Secretariado de la ISR a Lozovsky", Montevideo, el 7 de septiembre de 1928. RGASPI, Moscú. F. 503, inv. 1, exp. 19, f. 47.

70 “El acta sobre la Constitución”, 105, 109.
} 
No obstante, el rumbo hacia la unión sindical fue obstaculizado desde mero inicio. Mientras el Comité Organizador hablaba sobre la necesidad de contactar no sólo con todos los centros sindicales, sino con algunos otros sindicatos "sin importar las corrientes", sugería a los aspirantes participar en el Congreso Constituyente de la CSLA en Montevideo, y celebrar los congresos nacionales con el objetivo de "unificar todas las corrientes". Considerando la posibilidad de que las invitaciones pudieran ser "enviadas a la papelera" por algunos dirigentes de centrales sindicales nacionales, el Comité decidió contactar directamente con los sindicatos que formaban su parte, pero sólo en el caso cuando los altos mandos de la central sindical nacional rechazaran desde principio la posibilidad de asistir al Congreso. ${ }^{71}$ Por ejemplo, invitando a Montevideo a las centrales sindicales de Argentina, la Confederación Obrera Argentina (COA) y la Federación Obrera Regional Argentina (FORA), el Comité tomaba en cuenta la poca probabilidad de que estas participasen, ya que la COA anhelaba convertirse en el fundamento de la Federación Sindical Iberoamericana, orientada a la Internacional de Ginebra y el deseo de la FORA era convocar (con la ayuda de la Internacional Sindical de Ámsterdam) a un Congreso Continental de sindicatos de tendencia anarquista y anarco-sindicalista. En el caso de la reformista Confederación Regional Obrera Mexicana (CROM), el Comité Preparatorio no esperaba ver la asistencia de los dirigentes reformistas, sino atraer a Montevideo a los representantes de la "fuerte minoría revolucionaria". ${ }^{72}$

En el mismo Comité desde el principio las relaciones entre los representantes de diferentes corrientes sindicales eran bastante peculiares. Por un lado, Biondi, como si fuera comprobando la sinceridad de la declaración de los comunistas sobre el compromiso de acción conjunta, propuso llevar a cabo la campaña internacional por la libertad del anarquista Simón Radowitzky, acusado de asesinato, el 14 de noviembre de 1919, del jefe de la policía bonaerense, coronel Falcón. En 1928-1929 la campaña a favor del anarquista encarcelado no dio ningún resultado, sin embargo, Radowitzky fue finalmente amnistiado por la directriz del Presidente Hipólito Irigoyen y deportado al Uruguay en 1930, años después murió en exilio en México. ${ }^{73}$

Por otro lado, el representante de la USA tomó con calma la perspectiva de obtener patrocinio de parte de la Internacional Sindical Roja y de parte de los sindicatos izquierdistas de Francia, los EEUU y Gran Bretaña durante la preparación del Congreso. Al mismo tiempo que el comunista uruguayo Eugenio Gómez hablaba de la necesidad de "un tono" en la cobertura mediática del asunto presupuestario para evitar las protestas contra la intervención de la Moscú (o sea de la Profintern) en el trabajo del Comité, Biondi no veía motivo de perturbación: "Todo el mundo sabe sobre la postura positiva de la ISR respecto a la conferencia". ${ }^{74}$

La tarea de elegir el nombre definitivo del Comité resultó ser una cosa difícil. En la resolución de la Conferencia de Moscú se hablaba del "Comité para convocar al Congreso Constituyente de la Organización Continental Latinoamericana". Este nombre, que no llevaba una carga propagandista, no convenía a los organizadores, considerando el enfrentamiento de la Internacional Sindical Roja con las Internacionales de Ámsterdam y Ginebra, que planeaban crear sus propias federaciones continentales. Así, apareció la necesidad de inventar un nombre corto, como declaró Eugenio Gómez, nombre que reflejaría el espíritu luchador de los trabajadores. Su proposición era denominar el Comité como "el Comité por la Confederación Sindical Latinoamericana" lo que fue a fin de cuentas aceptado por los demás. ${ }^{75}$

Esta estructura creada para llevar a cabo el trabajo rutinario estaba compuesta de gente que tenía posibilidad de estar más o menos permanentemente en Montevideo: el argentino Miguel Contreras (elegido como el Secretario del Comité) y los uruguayos Eugenio Gómez y Juan Llorca. Se destacaba

71 "El acta sobre la Constitución", 110.

72 Ibid., 112.

73 Rubens Iskaro, Rabocheie i profsoyuznoie dviz̧heniie v Argentine: istoriia i razvitiie, Moscú, Progréss, 1978, 121-125; O.Bayer, Los anarquistas expropriadores, Simón Radowitzky y otros ensayos, Buenos Aires, Galerna, 1975, 79-119.

74 "El acta sobre la Constitución". Op. cit, 114.

75 "Ibid., 110-111. 
especialmente la participación en el trabajo del Comité de su secretario técnico, Carlos Dujovne, funcionario a sueldo de la Internacional Sindical Roja y enviado desde Moscú por solicitud de los organizadores del Congreso. No menos importante era el papel desempeñado por el delegado de la CGTU francesa, cuya central estaba dispuesta a ayudar al Comité en sus iniciativas y hasta prestarle un apoyo financiero. ${ }^{76}$ En los documentos constituyentes no está indicado el nombre del delegado de los sindicatos franceses y no queda claro si los integrantes de la sesión se habían enterado que el emisario de la CGTU era, efectivamente, el otro delegado plenipotenciario de la Internacional Sindical Roja, miembro del Secretariado Sudamericano de la Comintern, Maurice Jaskin (miembro del Partido Comunista ruso). A él le tocó coordinar todas las labores organizativas.

En todos los países representados se iban organizando los comités de apoyo a la convocatoria del Congreso Sindical Continental. Para aumentar sus posibilidades de propaganda, el Comité empezó la edición de la revista El Trabajador Latino Americano y decidió publicar la "Pequeña Biblioteca Sindical", una serie de folletos y libros sobre los problemas del movimiento obrero, teniendo en cuenta que entre ellos estarían trabajos del marxista italiano Antonio Labriola, el anarco-sindicalista francés Georges Sorel, el anarquista español Angel Pestaña, etc.

Durante la preparación del Congreso Continental la Internacional Sindical Roja envió a América Latina el grupo de emisarios más numeroso en toda la historia de las actividades en el Hemisferio Occidental de esta unión internacional sindical de organizaciones laborales pro-moscovitas. Lo integraban el francés Octave Rabate, representante general de la Internacional Sindical Roja en Sudamérica, el italiano Ennio Gniudi (“Orestes”) y el español Ramón Casanellas Lluch ("Floreal”) (estos dos trabajaban, sobre todo, en México), y los arriba mencionados Maurice Jaskin y Carlos Dujovne, que se instalaron en Montevideo. Aparte de ellos, los miembros del Subcomité del Caribe desempeñaban funciones de delegados para los países de América Central y del Caribe; eran el mexicano David Alfaro Siqueiros, los cubanos Leonardo Fernández Sánchez y Sandalio Junco. Más tarde a la lista se unió el venezolano Ricardo A. Martínez.

Todos los comunistas partícipes del trabajo preparatorio del Congreso, tanto los delegados enviados desde Moscú cómo los delegados latinoamericanos nombrados al Comité Organizador por la Segunda Conferencia Sindical Latinoamericana, trabajaron en contacto estrecho con el Secretariado Sudamericano de la Comintern y los partidos comunistas nacionales. Esta labor conjunta rindió sus frutos, no obstante, también reveló varios defectos y conflictos, que fueron colocados inicialmente en la estructura de las relaciones entre los comunistas latinoamericanos y las organizaciones sindicales, de un lado, y la Internacional Sindical Roja, del otro.

A fin y al cabo era la representación amplia de América Latina durante la Celebración del X aniversario de la Revolución de Octubre la que dio nuevo impulso al desarrollo de los lazos organizativos y de ideas entre la Comintern y sus organizaciones afiliadas con el movimiento revolucionario y obrero continental. Efectivamente, los elevó a un nuevo y más alto nivel. No es por nada que el dirigente de la ISR, Solomón Losovsky, dijera que fue en el aniversario de la Revolución Bolchevique cuando "descubrió a América Latina". Celebrados en 1927, los eventos en Moscú fundaron las bases para el verdadero avance en el despliegue amplio del movimiento comunista continental, fueron ejes importantes del VI Congreso Mundial de la Comintern, de la Primera Conferencia Comunista Latinoamericana en Buenos Aires, en mayo de 1929, y del Congreso Sindical Latinoamericano (Montevideo, 1929).

\section{Consideraciones finales}

A través de este estudio hemos analizado los pormenores de la organización de los viajes de los latinoamericanos a los festejos del aniversario de la revolución bolchevique, así como el impacto de la

${ }^{76}$ Más sobre Carlos Dujovne véase en: Alicia Dujovne Ortiz, El Camarada Carlos. Itinerario de un enviado secreto, Madrid, Aguilar, 2007. 
celebración en el desarrollo del movimiento revolucionario en el subcontinente. Este análisis deja en evidencia que la amplia presencia de los delegados latinoamericanos en Moscú, muchos de los cuales no militaban en los PP.CC., dio a la Comintern la posibilidad de establecer enlaces sólidos con varias organizaciones revolucionarias y sindicales, formando las bases para las actividades posteriores de la III Internacional y de la ISR. Sin embargo, no se trató de una alianza absolutamente heterogénea. El clima de estalinización ya empezaba a sentirse poco a poco dentro de la Comintern, además, el argentino Victorio Codovilla, que se ocupaba de la organización de los viajes, aprovechaba su puesto para llevar conflictos internos dentro del comunismo argentino a nivel mundial, socavando de esta manera las labores cominternistas en el continente. El "caso de Rafael Greco" fue una, pero no la única muestra de este proceso.

Sin embargo, los trabajos preparativos sobre la organización sindical de los gremios latinoamericanos hecha en Moscú y durante las celebraciones y posteriormente a los festejos, dieron un paso seguro hacia la formación de una nueva central sindical en la región. Sin estas actividades previas, según pudimos concluir, la celebración exitosa del Congreso Sindical Latinoamericano en Montevideo no hubiera sido posible. Moscú consideraba muy importante esa labor y, consecuentemente, envió una brigada de emisarios hacia el subcontinente para llevar a cabo la línea de la ISR y de la III Internacional. Y, como otras veces, reproducía las viejas fallas: una alianza basada, sobre todo, en la afinidad ideológica, lo que implicaba nuevas rupturas desde el principio y hacía poco probable y aún imposible ampliar la Confederación Sindical Latinoamericana para abarcar amplios sectores no comunistas de la clase obrera latinoamericana. Esos defectos aún estaban por desarrollarse, sin embargo, un resultado mucho más visible por el momento era el aumento del peso de los asuntos latinoamericanos en la agenda cominternista y un verdadero "descubrimiento" del subcontinente hecha por la Internacional Comunista durante 1927-1928.

\section{Fuentes}

\section{Archivos:}

Museo de la Historia Contemporánea de Rusia, Moscú.

F. 11811/51a, fs. 353-11B

F. $11811 / 516$, fs. 354-11B

F. 11811/29, fs. 354-11B.

RGASPI Archivo Estatal de Historia Social y Política, Moscu (en ruso: РГАСПИ)

"A la Comisaría de Organización de Delegaciones para el Aniversario de la Revolución de Octubre", Moscú, a 8 de noviembre de 1927. RGASPI, Moscú. F. 495, inv. 190, exp. 137.

"El Acta sobre la constitución del Comité de Ayuda a la Confederación Latinoamericana de Trabajo, efectuada el lunes, el 3 de septiembre de 1928”. RGASPI, Moscú. F. 534, inv. 4, exp. 219, fs. 105-106.

“Anexo a la nota del camarada Lozovsky”, Moscú, a 13 de febrero de 1928. RGASPI, Moscú. F. 534, inv. 8, exp. 94, f. 2.

"Carta del Jefe del Buró del Secretariado del CEIC M. Heimo al Departamento Organizativo de la Profintern, al camarada Gey”, Moscú, a 14 de diciembre de 1927. RGASPI, Moscú. F. 495, inv. 190, exp. 137, s.f.

"Carta de J. Humbert-Droz al Comité Central del Partido Comunista...”, Moscú, a 3 de marzo de 1928. RGASPI, Moscú. F. 49 "Carta de L. Fernández Sánchez a V. Codovilla”, París, a 3 de octubre de 1927. RGASPI, Moscú. F. 503, inv. 1, exp. 25, f. 30.

"Carta de A. Lozovsky al Secretariado Político del CEIC [Humbert-Droz]", Moscú, a 27 de enero de 1928. RGASPI, Moscú. F. 495, inv. 190, exp. 137, s.f. 
"Carta del Secretario del SSAIC V. Codovilla al Secretariado Latinoamericano de la Comintern [a Humbert-Droz]", Buenos Aires, a 5 de septiembre de 1928. RGASPI, Moscú. F. 503, inv. 1, exp. 19, f. 37.

"Carta del Secretario General del Comité Sindical Latinoamericano M. Contreras al Secretariado de la ISR (a Lozovsky)”, Montevideo, a 7 de septiembre de 1928. RGASPI, Moscú. F. 503, inv. 1, exp. 19, f. 47.

"La declaración de la delegación latinoamericana", Moscú, a 1927. RGASPI, Moscú. F. 495, inv. 79, exp. 26, f. 4.

“Las explicaciones de Gey a Pyátnitsky”, Moscú, a 17 de diciembre de 1927. RGASPI, Moscú. F. 495, inv. 190, exp. 137, s.f.

"Nota de Lozóvskiy al Politburó del TsK VKPb/ "Sobre el presupuesto de los Secretariados Sindicales del Océano Pacífico y América Latina”", Moscú, a 2 de marzo de 1928. RGASPI, Moscú. F. 534, inv. 8 , exp. 94, f. 7.

"Nota de Lozovsky al Politburó del TsK VKPb/ "Sobre el presupuesto para el trabajo en la costa del Océano Pacífico y en América Latina"”, Moscú, a 13 de febrero de 1928. RGASPI, Moscú. F. 534, inv. 8, exp. 94.

"Nota de Lozovsky al Secretariado Político del CEIC (a Pyátnitsky) "Sobre el trabajo de Brauder y Harrison George"”, Moscú, a9 de febrero de 1929. RGASPI. F. 495, inv. 3, exp. 143, f. 36.

"Nota [de Lozovsky] al Secretariado del TsK VKPb [a Kossior]", Moscú, a 12 abril de 1928. RGASPI, Moscú. F. 534, inv. 8, exp. 94, f. 12.

"Nota [de Lozovsky] al Secretariado del TsK VKPb [a Kossior]", Moscú,a 11 de mayo de 1928. RGASPI, Moscú. F. 534, inv. 8, exp. 94, f.21.

"Nota explicativa de cam. Gey al Secretariado del CEIC (Mauno Heimo)", Moscú, a 8 de diciembre de 1927. RGASPI, Moscú. F. 495, inv. 190, exp. 137, s.f.

“Telegrama de Codovilla a A. Castineiras”, Moscú, a 12 de septiembre de 1927. RGASPI, Moscú. F. 495, inv. 79, exp. 25, f. 10.

“Telegrama de Codovilla al Dr. A. Palacios”, Moscú, a 12 de septiembre de 1927. RGASPI, Moscú. F. 495, inv. 79, exp. 25, f. 11.

"Telegrama de Codovilla a Concentrus", Moscú, a 1927. RGASPI, Moscú. F. 495, inv. 79, exp. 25, f. 41. “Telegrama de Codovilla a J. Penelón”, Moscú, a 1927. RGASPI. F. 495, inv. 79, exp. 25, f. 45.

“Telegrama de Garl[andi] a Penelón”, Moscú, a 23 de noviembre de 1927. RGASPI, Moscú. F. 495, inv. 134, exp. 105, f. 42.

"Telegrama de T. González, el Secretario general de la USA, a S. Lozovsky", Moscú, a 27 de enero de 1928. RGASPI, Moscú. F. 495, inv. 190, exp. 137, s.f.

“Telegrama de V. Codovilla a Penelón”, Moscú, antes del 12 de septiembre de 1927. RGASPI Moscú, Moscú. F. 495, inv. 134, exp. 106, f. 9.

“Telegrama de V. Codovilla a A. Ghioldi”, Moscú, a 1927. RGASPI Moscú. F. 495, inv. 79, exp. 25, f. 55 .

“Telegramas de V. Codovilla a Leiros, J. Pimenta”, Moscú, a 1927. RGASPI, Moscú. F. 495, inv. 79, ex. 25, ff. 49, 53.

"Telegrama del Presidente de la Comisión de Relaciones Internacionales del CC del Consejo PanSoviético de los Sindicatos Yanglóm a Alonso (la Unión Sindical Argentina), Moscú, a 1927. RGASPI, Moscú. F. 495, inv. 134, exp. 105, f. 70.

"Telegramas de Codovilla a L. Sala (Uruguay), J.F. Carolis (Ecuador), Penelón, Romo, Alonso (Argentina)". RGASPI, Moscú. F. 495, inv. 79, exp. 25, ff. 42-44.

"Telegramas de Codovilla a Penelón, al deputado Pérez Leiros (Buenos Aires), Fritz Bach (México)". RGASPI, Moscú. F. 495, inv. 79, exp. 25, ff. 47, 53. 


\section{PRENSA:}

Bakinskiy Rabochiy, Bakú

Izvestia, Moscú

Komsomolskaia Pravda, Moscú

Krasnaia Gazeta, Leningrado

Latinskaia Amerika, Moscú

Leningradskaia Pravda, Leningrado

Novaia i noveishaia istoriia, Moscú

Pravda, Moscú

Trud, Moscú

\section{FUENTES PUBLICADAS}

X Plenum Ispolkoma Kominterna. Vyp. 3. Ekonomicheskaia bor'ba i zadachi Kommunisticheskoi partii, Moscú, Gosudárstvennoe Izdátelstvo, 1929.

Ghioldi, Rodolfo. Ižbrannye statyi i rechi, Moscú, Politizdát, 1979.

Lenin, Vladimir Illich, "Discurso en la Conferencia Amplia de obreros y soldados del Ejército Rojo en el barrio Rogózhsko-Símonovskiy el 13 de mayo de 1920. Reportaje periodístico”. En: Lenin, Vladimir Illich. Polnoie Sobraniie Sochinenii, Tomo 41, Moscú, Politizdat, 1981.

Losovsky, Abram. El Movimiento Sindical Latino Americano. Sus virtudes y sus defectos, Montevideo, Comite Pro Confederación Sindical Latino Americana, 1929.

Recabarren, Luis Emilio. Izbrannye statyi i rechi, Moscú, Politizdát, 1977.

\section{BIBLIOGRAFIA:}

Alexander, Robert J. Communism in Latin America, New Jersey, Rutgers University Press, 1957.

Bayer, O. Los anarquistas expropriadores, Simón Radowitzky y otros ensayos. Buenos Aires, Galerna, 1975.

Caballero, Manuel. La Internacional Comunista y la revolución latinoamericana, Caracás, Editorial Nueva Sociedad, 1987.

Camarero, Hernán. A la conquista de la clase obrera. Los comunistas y el mundo del trabajo en la Argentina, 1920 1935, Buenos Aires, Siglo XXI, 2007.

Dónskiy, Grigory. Bor'ba za Latinskuyu Ameriku, Moscú-Leningrado, Moskóvskiy rabóchiy, 1928.

Dujovne Ortiz, Alicia. El Camarada Carlos. Itinerario de un enviado secreto. Madrid: Aguilar, 2007.

Goldenberg, Boris. Kommunismus in Lateinamerika, Stuttgart, Berlin, Köln, Mainz, Kohlhammer, 1971.

Iskaro, Rubens. Rabocheiie i profsoyuznoie dvizhenïie v Argentine: istorïa i razvitiie. Moscú, Progreso, 1978.

Jeifets, Lazar. “"Para contar la verdad sobre la URSS”. (Primeras delegaciones latinoamericanas en la Unión Soviética)". Latinskaia Amerika, núm. 12, Moscú, 1982, 373-383.

Jeifets, Lazar, Víctor Jeifets. América Latina en la Internacional Comunista, 1919-1943. Diccionario biográfico, Santiago, Ariadna, 2015.

Jeifets, Lazar, Jeifets, Víctor. "La Comintern y la formación de militantes comunistas latinoamericanos". Izquierdas, 2016, N31, Santiago, 130-161.

Jeifets, Víctor. Komintern i evolutsiia levogo dviz̨heniia Meksiki, San Petersburgo, Nauka, 2006.

Kersfeld, Daniel. Contra el Imperio. Historia de la Liga Antimperialista de las Américas, México, Siglo XXI, 2012.

Loyola, Manuel. "La asociación de amigos de la Unión Soviética en Chile, 1927-1943", Estudos IberoAmericanos, vol. 42, n.1, Porto Alegre, 308-326.

Pintos, Franciso R. Profsoyuznoie dviz̨heniie Uruguaia, Moscú, Profizdát, 1964.

Pintos, Francisco R. "Vliyaniie leninizma na rabocheie dvizheniie Uruguia". Novaia i noveishaia istoriia, núm. 2, Moscú, 1960. 
Víctor Jeifets - Lazar Jeifets, Los latinoamericanos en la Celebración del X Aniversario de la Revolución Rusa y la preparacion del Congreso Sindical Latinoamericano, Izquierdas, 48, noviembre 2019:64-86

Rojas Blaquier, Angelina. Primer Partido Comunista de Cuba. Sus tácticas y estrategias. 1925-1935. Tomos 1-2. Santiago de Cuba, Editorial Oriente, 2005.

Salazar Rosendo, y Escobedo, José G. Las pugnas de 1 a g1eba (Los a1bores del movimiento obrezo en México, México, Editorial del PRI, 1972.

Tarcus, Horacio (dir.). Diccionario biográfico de la izquierda argentina. Buenos Aires, Emece, 2007.

Tosstorf, Reiner. The Red International of Labor Unions, Boston, Brill, 2004. 